\title{
8
}
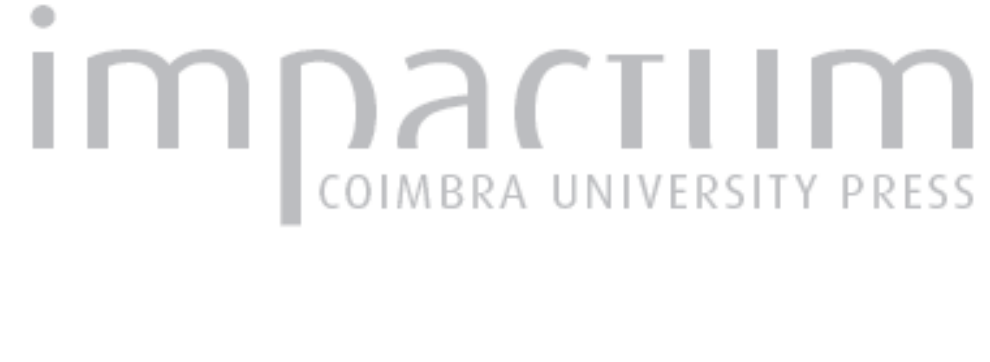

\section{[Recensão a] José Maria Solana Sainz, Autrigonia Romana, Zona de contacto Castilla-Vasconia}
Autor(es):
D’Encarnação, José

Publicado por: Imprensa da Universidade de Coimbra

URL persistente:

URI:http://hdl.handle.net/10316.2/45734

DOI:

DOI:https://dx.doi.org/10.14195/1647-8657_19_14

Accessed :

26-Apr-2023 08:49:58

A navegação consulta e descarregamento dos títulos inseridos nas Bibliotecas Digitais UC Digitalis, UC Pombalina e UC Impactum, pressupõem a aceitação plena e sem reservas dos Termos e Condições de Uso destas Bibliotecas Digitais, disponíveis em https://digitalis.uc.pt/pt-pt/termos.

Conforme exposto nos referidos Termos e Condições de Uso, o descarregamento de títulos de acesso restrito requer uma licença válida de autorização devendo o utilizador aceder ao(s) documento(s) a partir de um endereço de IP da instituição detentora da supramencionada licença.

Ao utilizador é apenas permitido o descarregamento para uso pessoal, pelo que o emprego do(s) título(s) descarregado(s) para outro fim, designadamente comercial, carece de autorização do respetivo autor ou editor da obra.

Na medida em que todas as obras da UC Digitalis se encontram protegidas pelo Código do Direito de Autor e Direitos Conexos e demais legislação aplicável, toda a cópia, parcial ou total, deste documento, nos casos em que é legalmente admitida, deverá conter ou fazer-se acompanhar por este aviso.

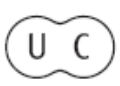


FACULDADE DE LETRAS

INSTITUTO DE ARQUEOLOGIA

CONIMBRIGA

VOLUME XIX

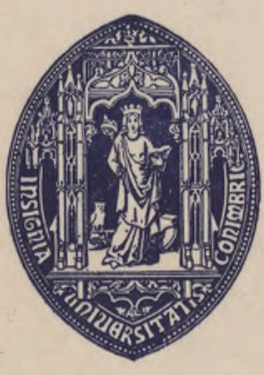

UNIVERSIDADE DE COIMBRA

1980 
- Chaves (p. 38) não é citada;

- Bormanicus (p. 37) aparece sob a forma de Reus (?) Bormanicus, mas Bormanus (p. 37 n. ${ }^{\circ} 28$ ) não é citado;

- Rhea não é só 34 , é também 37 n. ${ }^{\circ} 31$;

- Coronus (p. 35 n. ${ }^{\circ} 20$ ) não é referido.

São, dum modo geral, boas as fotografias apresentadas. Estranhamos, porém, que o director do Museu de Lugo, co-autor do volume, não tenha podido retirar das peças, para as fotografar, as placas identificativas (supomos que o sejam, porque não se explica se há números de inventário no Museu)* placas altamente inestéticas e que já contradizem os modernos conceitos museológicos (veja-se logo a planche /...).

E se - reportando-nos de novo ao estudo das epígrafes - continuamos a não compreender a existência nas aras de campos epigráficos tridimensionais, outros pormenores serão de ter em conta:

- $N .^{\circ}$ 23: uma vez que, embora como hipótese, se reconstitui a invocação I.O.M., não seria de colocar este texto na sequência das dedicatórias a Júpiter? A sua importância para o estudo da religião em geral — mais do que para o culto imperial —* é inegável.

-.$^{\circ}$ 57: «Cohvetena deve aproximar-se duma outra divindade conhecida sob o nome de Covetina, que sofreu numerosas variantes ortográficas». Esta não será uma das variantes?

- $N .^{\circ}$ 63: A pedra não permite uma leitura tão evidente quanto a reconstituição o dá a entender. A existência duma linha com o cognome do dedicante é postulada pelas dimensões do monumento e pelo próprio texto. As 1.1 e 2 não nos parecem claras.

- $N .^{\circ}$ 64: Não é claro que o dedicante tenha os tria nomina. A nota 27 refere o nomen Auge, que é, afinal, um teónimo (ILER 746).

- $N .^{\circ}$ 80: A interpretação é duvidosa, pelo menos no que respeita à intercalação de uxor.

O livro honra os seus autores e, embora não revele o fôlego histórico que lhes conhecemos, será doravante obra de referência obrigatória.

JOSÉ D'ENCARNAÇAO

José Maria Solana Sainz, Autrigonia Romana, Zona de contacto Castilla-Vasconia, Departamento de Historia Antigua. Universidad de Valladolid, Valladolid 1978, 495 pág., mapas e 81 fotos.

Tese de doutoramento em 1974 e só publicada em 1978, Autrigonia Romana apresenta-se como urna obra polémica, afirmativa: usando novos métodos e compilando todos os materiais arqueológicos disponíveis (muitos 
deles inéditos) (p. 14); re-estudando dados escassos até então alinhados sem carácter científico; criticando asperamente A. Abásolo (p. 115, 144-5, por exemplo); estudando «em condições» (p. 171) uma onomástica cujos «dados ricos» noutras ocasiões se depreciaram «ao fazer da epigrafia um mero catálogo».

O volume é efectivamente extenso e abarca todos os domínios, como se pode ver pela síntese do seu conteúdo: o cap. I estuda os nomes e os topónimos de Autrigonia romana, bem como os seus limites geográficos. O cap. II debruça-se sobre a geografia física. Um estudo linguístico, baseado nos dados epigráficos, ocupa o extenso cap. Ill (p. 93-230). A reconstituição da rede viária romana é tentada no cap. IY, para se analisarem, nos dois capítulos seguintes, a toponimia de influencia romana $\mathrm{e}$ as manchas de povoamento no período hispano-romano. Termina a obra pelos índices (antropotoponímico e geral), mapas e fotografías.

Os quatro anos que mediaram entre a feitura do trabalho e a sua publicação decerto contribuíram para que se tornassem menos novos e menos acutilantes os métodos apontados. Porque se era novidade então uma perspectiva de historia global, em que todos os dados disponíveis são tidos em consideração, o mesmo já não aconteceria em 1978. E com respeito a métodos, por mais inovadores que sejam, eles hão-de basear-se numa análise cuidada, inteligente, sem conclusões precipitadas. Assim, por exemplo, se ao tentar um esboço demográfico, o autor expõe bem (p. 129-131) as difículdades das estatísticas, o certo é que acaba por dar percentagens da população, por afirmar que a maior mortalidade se situa entre os 20 e os 30 anos, apresentando gráficos e quadros de 16 (dezasseis) inscrições, datáveis dos séculos I-V (p. 134-141).

Ao focar a antroponimia, não nos parece ter razão de ser a separação masculino / feminino, com comentários e bibliografia distintos. Um antropónimo como Ambada deve ser estudado juntamente com Ambatus - para uma distribuição onomástica, o género não importa. Por outro lado, há que distinguir bem um praenomen (mesmo por extenso) dum gentilicio; afirmar que Publius é um antropónimo «escassamento representado na Península» (quatro exemplos) (pág. 165) torna-se problemático; o mesmo se diga em relação a Caius (p. 161), Lucius (p. 163) e Marcus (p. 164); deste último se diz que, no CIL II, há treze exemplos: como nomen? Em terceiro lugar, teremos que rever noções como «frequente», «muito frequente», que - embora subjectivas-começam a ganhar foros de objectividade: se de Aufidius há 16 exemplos na Península poder-se-á dizer que este nomen é «frequente» (p. 161)? Se, no CIL II, há 14 (catorze) exemplos de Lucius, este antropónimo é «muito frequente» (p. 163)? Aliás, apesar das cautelas a ter, as Inscripciones Latinas de la España Romana, de José Vives (Barcelona, 1971, 1972), são de citação obrigatória neste domínio da ocorrência de antropónimos.

Os textos epigráficos constituem parte importante da tese. De cada um, Solana Sainz refere: local de achado, material, dimensões, campo epigráfico, transcrição, interpretação, tradução e bibliografia, com alguns pormenores 
em nota. Não se alude a variantes de leitura, não se remete para a foto eventualmente incluida no final do volume, não se fazem comentários paleográficos ou históricos - a antroponímia é analisada depois, por ordem alfabética. Os textos são apresentados por províncias e ordem alfabética do local de achado; mas para os da mesma proveniência não se vislumbra um critério de arrumação.

Não sendo possível um rastreio completo de pontos discutíveis - que, aliás, só o frequente manuseamento permite detectar — apontamos alguns:

- Na inscrição 9b Q. não é necessariamente desdobrável em Q(uirina), pode ser Q(uinti filio), o que vem alterar o teor dalguns comentários (p. 170);

- o n. ${ }^{\circ} 20$ (p. 105) annorum VII S, S significa semis: o defunto tinha sete anos e meio;

— o n. ${ }^{\circ} 22$ é mesmo de identificar com o 15 ;

- n. ${ }^{\circ}$ 63: a bibliografia é indicada duas vezes;

— n. ${ }^{\circ} 69$ (p. 179): o texto é dedicado a I.O.M. CONS(ereatori);

— n. 70 preferimos EXS VOTO (exs por ex) em vez de ex s(uscepto) voto;

- no domínio da toponímia (cap. V), há que proceder com prudência: se Aguilar provém de «aquila» (p. 363), poderá isto significar «uma profunda romanização» (p. 388)?

- não apresenta o Autor a bibliografia à parte, o que dificulta a pesquisa. Livros deste género são, cada vez mais, obras de consulta e não de leitura seguida, de sorte que se numa nota se encontra apenas a referência «Forcellini», pode gastar-se muito tempo (como nos aconteceu) para descobrir, bastantes páginas antes, qual a obra de Forcellini a que a nota se reportava.

Nas conclusões (p. 463-482), Solana Sainz resume os dados obtidos em cada capítulo, focando a história da Autrigónia desde a vinda dos centro-europeus Autrigones até ao Baixo Império inclusive, concluindo que se assistiu à sua paulatina romanização a partir dos começos de séc. i da nossa era, mais acentuada nos séc. $\mathrm{n}$ e $\mathrm{m}$, com maior intensidade na região da Bureba, embora as sobrevivências indígenas se tenham mantido fortemente.

Pelo seu carácter global, e pelo acervo de informações que contém, «Autrigónia Romana» constitui elemento de consulta obrigatória para quem se queira debruçar sobre a história desta região do Norte peninsular.

JOSÉ D'ENCARNAÇ̃̃o 